\title{
Koersontwikkeling van geprivatiseerde onder- nemingen op lange termijn
}

\author{
Dr.F.E. Huibers
}

\section{$1 \quad$ Inleiding}

Sinds Margaret Thatcher in 1979 het startschot loste, zijn wereldwijd een groot aantal staatsbedrijven door middel van beursintroducties verkocht.

Alleen al in het Verenigd Koninkrijk zijn in de periode 1979-1991 voor ruim GPB 34 miljard alan aandelen van staatsbedrijven op de beurs geïntroduceerd (ter vergelijking: in dezelfde periode was de waarde van nieuw-genoteerde particuliere ondernemingen een kleine GBP 5 miljard). Ook in andere Europese landen als Frankrijk, Spanje en Nederland hebben beursintroducties van staatsbedrijven een groot deel van het uitgiftevolume voor hun rekening genomen. Buiten Europa is privatisering door middel van aandelenintroducties veelvuldig uitgevoerd in Latijns-Amerika (onder andere in Mexico, Argentinië en Chili) en Azië (onder andere in Singapore en Maleisië). Gelet op de omvangrijke privatiseringsplannen die landen als Italië, Japan, India en Brazilië hebben aangekondigd, ziet het ernaar uit dat in de komende jaren het volume van aandelenintroducties van staatsbedrijven hoog zal blijven.

$\mathrm{Nu}$ is de vaststelling van een uitgiftekoers bij aandelenintroducties in het algemeen en bij privatiseringen in het bijzonder een belangrijk probleem. Er bestaat immers geen beurskoers die als referentiepunt gebruikt kan worden.

Empirisch onderzoek' aangaande diverse aandelenmarkten in de wereld heeft aangetoond dat de eerste beurskoers van geïntroduceerde

Dr. F.E. Huibers, gepromoveerd aan de Katholieke Universiteit Brabant, is werkzaam als Hoofd Asset Management van Rabobank Nederland te Utrecht. aandelen gemiddeld hoger ligt dan de uitgiftekoers, rekening houdend met markttendenties. Men spreekt dan van 'underpricing'.

Volgens de critici van privatisering is de underpricing bij aandelenintroducties van staatsbedrijven gemiddeld hoger dan de underpricing die zich voordoet bij aandelenintroducties van particuliere ondernemingen. Het verschil in de gemiddelde underpricing tussen de twee groepen aandelenintroducties wordt het underpricing differentieel genoemd.

Onderzoek ${ }^{2}$ op de diverse aandelenbeurzen waar een groot aantal aandelenintroducties van staatsbedrijven zijn uitgevoerd, heeft aangetoond dat het underpricing differentieel zich daadwerkelijk voordoet en het gevolg is van de doelstelling van de overheid om het aandelenbezit onder burgers te verbreden. Daarmee lijkt de kritiek, dat de aandelen van staatsbedrijven relatief goedkoop op de beurs geïntroduceerd worden, gerechtvalardigd.

Echter. de resultaten van recent onderzoek naar het meerjarige koersverloop van aandelenintroducties zet vraagtekens bij de conclusie dat de uitgiftekoers doorgaans te laag vastgesteld wordt. De studies geven aan dat aandelenintroducties op de lange termijn (in een periode tot maximaal drie jaar na introductie) gemiddeld genomen een negatief koersverloop laten zien ten opzichte van de marktindex. Volgens deze studies zijn de hoge initiële rendementen op aandelenintroducties (de onderzoeken verkiezen het begrip 'initieel rendement' boven het begrip 'underpricing's) niet zozeer het gevolg van een te lage vaststelling van de uitgiftekoers maar worden daarentegen veroorzaakt doordat overoptimistische beleggers tijdens de eerste handelsdagen de beurskoers van de geïntroduceerde aandelen te hoog opdrijven. Op de 
langere termijn ebt de initiële euforie rondom de aandelenintroductie weg en vallen de aandelen terug naar meer rationele waarderingsniveaus.

Het pionierswerk dat Aggarwal en Rivoli in 1990 verrichtten aangaande de theorie-vorming op het gebied van overoptimisme bij aandelenintroducties, is in de daaropvolgende jaren verder uitgewerkt door Shiller (1990) en Ritter (1991).

De belangrijke empirisch toetsbare hypothese van deze verklaring voor de hoge initiële rendementen bij aandelenintroducties is, dat er een significant negatief verband bestaat tussen het initiële rendement en de mate van underperformance van de aandelen ten opzichte van de marktindex in de periode na de eerst dag van notering.

Immers, hoe geprononceerder het overoptimisme van beleggers in de eerste dagen van notering (resulterend in een koers die beduidend boven de uitgifteprijs ligt), hoe sterker de neerwaartse bijstelling van de koers als de irrationele euforie geleidelijk verdwijnt.

Volgens de overoptimisme-hypothese wordt de uitgifteprijs van aandelenintroducties, gemiddeld genomen, op een 'correct' niveau vastgesteld. Het underpricing verschijnsel is een tijdelijke aberratie: de koers van de aandelenintroductie zal op de langere termijn terugvallen in de richting van de uitgifteprijs.

Volgens de underpricing-hypothese, daarentegen, wordt de uitgifteprijs doorgaans wél te laag vastgesteld. Er is dan ook geen sprake van een systematische underperformance van aandelenintroducties op de lange termijn omdat de marktpartijen die de eerste beurskoersen tot stand doen komen, rationeel handelen. De underpricinghypothese voorspelt derhalve dat er geen significant verband tussen het initieel rendement van aandelenintroducties en het relatieve koersverloop in de jaren na introductie zal bestaan.

De gemiddeld hogere initiële rendementen bij privatiseringen zijn volgens de overoptimismehypothese het gevolg van de enorme advertentiecampagnes waarmee deze aandelenintroducties doorgaans gepaard gaan. Het irrationele beleggingsgedrag is bij aandelenintroducties van particuliere ondernemingen volgens de overoptimisme-hypothese veel minder geprononceerd doordat er aanzienlijk minder publiciteit rond deze introducties bestaat.
Volgens de underpricing-hypothese zijn de initiële rendementen bij privatisering hoger dan bij andere aandelenintroducties omdat de overheid met het oog op de verbreding van individueel aandelenbezit de uitgifteprijs op een relatief laag niveau vaststelt.

In schema 1 wordt een overzicht van de overoptimisme- en de underpricing-hypothese gegeven.

Schema 1: Overzicht van de overoptimisme- en de underpricing-hypothese in relatie tot voorspelde initieel rendement (IR) en aftermarket rendement (AR) van aandelenintroducties

\begin{tabular}{lll}
\hline Hypothese & IR & AR \\
\hline Overoptimisme & Significant positief & Significant negatief \\
Underpricing & Significant positief & Niet significant \\
\hline
\end{tabular}

In grafiek 1 en 2 wordt het voorspelde koersverloop van een aandelenintroductie weergegeven volgens, respectievelijk, de overoptimisme- en de underpricing-hypothese.

Grafiek I: het voorspelde koersverloop van een aandelenintroductie volgens de overoptimisme-hypothese

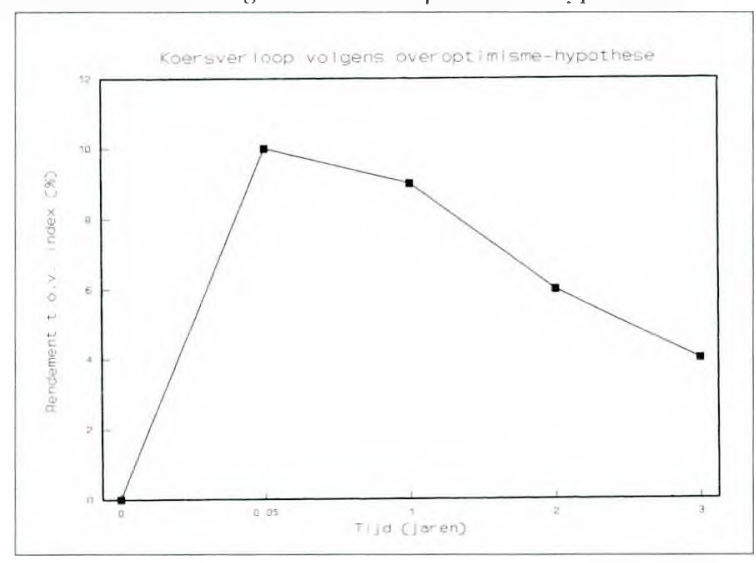

Grafiek 2: het woorspelde koersverloop van een aandelenintroductie volgens de underpricing-hyporhese

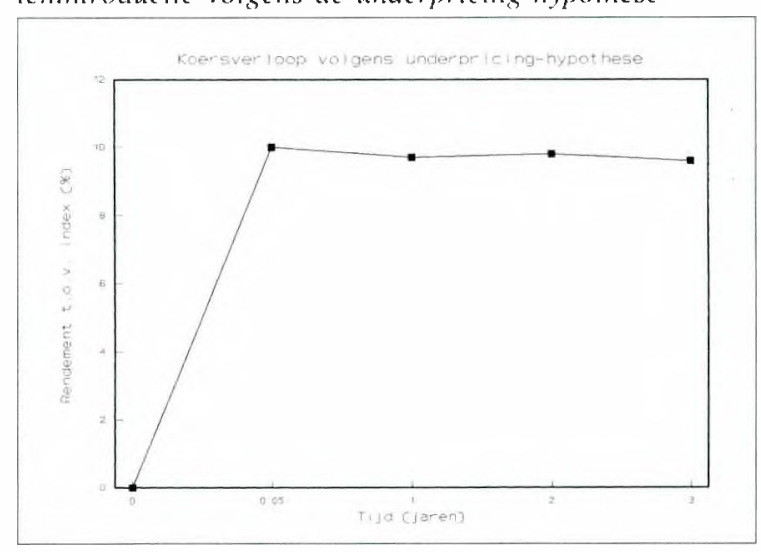


Doel van dit onderzoek is om aan te tonen dat ofwel de overoptimisme-hypothese ofwel de underpricing-hypothese een adequate verklaring biedt voor het verschil in gemiddeld initieel rendement van aandelenintroducties van staatsbedrijven en het gemiddeld rendement van aandelenintroducties van particuliere ondememingen.

\section{Bestaand onderzoek}

In tabel 1 wordt een overzicht gegeven van onderzoek naar het lange-termijnkoersverloop van aandelenintroducties. Het gemiddeld rendement van de aandelenintroducties wordt gemeten van de slotkoers van de eerste handelsdag tot 1 jaar na de eerste handelsdag. gecorrigeerd voor markıtendenties volgens formule (2) die in paragraaf 3 van dit artikel wordt vermeld. ${ }^{+}$Dit is het zogeheten aftermarket rendement (AR).

Bestaand onderzoek naar de lange-termijnkoersontwikkeling van aandelenintroducties, dat

Tabel 1: Overzicht van bestaand onderzoek naar de lange-termijnkoersontwikkeling van aandelenintroducties

\begin{tabular}{|c|c|c|c|c|}
\hline Auteurs & AR $(\%)$ & Aantial & Land & Periode \\
\hline \multicolumn{5}{|l|}{ Bear en } \\
\hline Curley (1975) & $-25.0^{*}$ & 140 & VS & 1969 \\
\hline Reilly (1977) & 9.7 & 233 & VS & $1972-1975$ \\
\hline \multicolumn{5}{|l|}{ Chalk en } \\
\hline Peavy (1987) & $17.90 *$ & 649 & VS & $1975-1982$ \\
\hline Dawson (1987) & -9.3 & 21 & HongK. & $1978-1983$ \\
\hline Dawson (1987) & -2.7 & 39 & Sing. & $1978-1983$ \\
\hline Dawson (1987) & $18,2^{*}$ & 21 & Mil. & $1978-1983$ \\
\hline \multicolumn{5}{|l|}{ Finn en } \\
\hline Higham (1988) & -6.52 & 93 & Austr. & $1966-1978$ \\
\hline \multicolumn{5}{|l|}{ Aggarwal en } \\
\hline Rivoli (1990) & $-13,73 *$ & 1435 & VS & 1977-1987 \\
\hline \multicolumn{5}{|l|}{ Eijgenhuijsen } \\
\hline en Buijs (1993) & $-0,72$ & 68 & Ned. & 1982-1991 \\
\hline Ritter $(1991)^{a}$ & $-27.39 *$ & 1526 & VS & $1975-1984$ \\
\hline Loughran (1993) & $-58.94^{*}$ & 36.56 & VS & $1968-1987$ \\
\hline Levis $(1993)$ & $-11,38$ & 712 & VK & $1980-1988$ \\
\hline \multicolumn{5}{|l|}{ Aggarwal } \\
\hline \multirow[t]{3}{*}{ et al. $(1993)^{\mathrm{a}}$} & $-47 .()^{*}$ & 48 & Braz. & $1980-1990$ \\
\hline & -23.7 & 18 & Chili & $1987-1990$ \\
\hline & -19.6 & 38 & Mex. & $1982-1990$ \\
\hline Keloharju (1993)i & $-26,4 *$ & 80 & Finl. & $1984-1989$ \\
\hline \multicolumn{5}{|c|}{$\begin{array}{l}\text { al }=\text { koersverloop alandelenintroducties over drie jailr na introductie } \\
*=\text { significant verschillend van nul bij een belrouwbuatheidsinter- } \\
\text { val mel } \alpha=0.05\end{array}$} \\
\hline
\end{tabular}

uitgevoerd is op diverse andelenbeurzen, levert een onvolledig beeld dat verre van eenduidig is.

In legenspraak met de overoptimisme-hypothese meten Reilly (1977), Chalk en Peavy (1987) en Dawson (1987), een positief gemiddeld rendement in plaats van de verwachte underperformance ten opzichte van de marktindex. In twee gevallen is dit positieve rendement statistisch significant.

Ten tweede is het beeld tevens niet eenduidig omdat in slechts zes van de dertien steekproeven die wel een negatief rendement meten, dit gemiddelde statistisch significant is.

De resultaten van bestaand onderzoek lijken geen overtuigende steun aan de overoptimismehypothese te bieden.

Daarnaast levert het bestaand onderzoek een onvolledig beeld op omdat mel uitzondering van Ritter (1991) en Levis (1993) er in de studies niel getoetst word of er een significant verband bestaat tussen het initicel rendement en de relatieve performance van de aandelenintroducties.

Zowel Ritter (1991) als Levis (1993) constateren dat er weliswaar een negatief verband bestaat tussen de twee grootheden, maar dat dit verband niet statistisch signilicant is.

Het beeld dat bestaand onderzoek oplevert is tevens onvolledig, omdat het geen inzicht geeft in de vraag of de overoptimisme-hypothese een verklaring biedt voor hel verschil in gemiddeld initieel rendement van de aandelenintroducties van staatsbedrijven versus die van particuliere ondernemingen.

\section{Onderzoeksmethode}

Volgens de overoptimisme-hypothese is er een significant negatief verband tussen het initieel rendement van een atandelenintroductie en de mate van underperformance in de daaropvolgende meerjarige periode.

In atansluiting op bestaand empirisch onderzoek naar het underpricing-verschijnsel. meten we het initieel rendement (IR) van een aandelenintroductie $i$ als weergegeven in formule $(1)^{6}$.

Om het koersverloop van aandelenintroductie $\mathrm{i}$ te meten, wordt het aftermarket rendement (AR) berekend volgens formule (2). 
$I R_{1}=\left[\left(P_{1},-I P_{1}\right) / I P_{1}\right]-\left[\left(I_{1}-I_{0}\right) / I_{0}\right]$

De gebruikte symbolen hebben de volgende betekenis:

$\mathrm{IR}_{1}=$ initieel rendement van aandelenintroductie $\mathrm{i}$;

$P_{11}=$ slotkoers op de eerste handelsdag van aandelenintroductie i:

$\mathrm{IP}_{1}=$ uitgifteprijs van aandelenintroductie $\mathrm{i}$;

$I_{1}=$ beursindex op de eerste handelsdag van aandelenintroductie $\mathrm{i}$;

$I_{0} \quad=$ beursindex op de dag dat de uitgifteprijs van aandelenintroductie $\mathrm{i}$ is vastgesteld.

$\mathrm{AR}_{\mathrm{t}, \mathrm{i}}=\left[\left(\mathrm{P}_{\mathrm{i}, \mathrm{l}}-\mathrm{P}_{\mathrm{i}, \mathrm{l}}\right) / \mathrm{P}_{\mathrm{i}, \mathrm{I}}\right]-\left[\left(\mathrm{I}_{1}-\mathrm{I}_{1}\right) / \mathrm{I}_{1}\right]$

De gebruikte symbolen hebben de volgende betekenis:

$\mathrm{AR}_{1}=$ aftermarket rendement van aandelenintroductie i na t jaar na de eerste handelsdag;

$P_{11}=$ slotkoers van aandelenintroductie i na $t$ jaar na de eerste handelsdag;

$\mathrm{P}_{i,}=$ slotkoers van aandelenintroductie $\mathrm{i}$ op de eerste handelsdag;

$I_{1}=$ beursindex value na $t$ jaar na de eerste handelsdag;

$I_{1}=$ beursindex op de eerste handelsdag van aandelenintroductie i.

In aansluiting op bestaand onderzoek inzake de koersvorming van aandelenintroducties (zie tabel 1), wordt geen risicocorrectie toegepast in de berekening van de initiële rendementen en aftermarket rendementen. De reden voor deze berekeningsmethode is dat de beta factor per definitie alleen $e x$ post kan worden vastgesteld. Deze $e x$ post calculatie levert onbetrouwbare resultaten op.

Bovendien blijkt uit het onderzoek van Ibbotson (1975) dat een proxy voor de beta factor in de periode na introductie niet stabiel is. Derhalve wordt bij de meting van initiële rendementen en aftermarket rendementen geen risicocorrigerende factor gehanteerd. Voor een overzicht van onderzoek naar het risicoprofiel van aandelenintroducties verwijzen wij naar Huibers (1994).

Voor zowel de groep van aandelenintroducties van staatsbedrijven als de groep van aandelenintroducties van particuliere ondernemingen wordt het gemiddelde initieel rendement (GIR) en het gemiddeld aftermarket return (GAR) berekend.

Om te toetsen of het GIR (of GAR ) significant verschilt van nul, wordt een t-toets uitgevoerd waarbij de t-waarde als volgt berekend wordt:
$t(G I R)=[G I R / \sigma(I R)] \vee N$

De gebruikte symbolen hebben de volgende betekenis:

$o ́\left(\mathrm{IR}_{1}\right)=$ standaarddeviatie van de initiële rendementen van $\mathrm{N}$ aandelenintroducties.

Voorts worden de parameters van het volgende regressiemodel geschat:

$\mathrm{AR}_{, 1}=\alpha+\beta \mathrm{IR}_{i}+\epsilon_{i}$
voor $t=1,2$ en 3 jaar.

Volgens de overoptimisme-hypothese zou de geschatte waarde van de $B$ parameter significant negatief moeten zijn. Daarnaast zou de underperformance van de aandelenintroducties van staatsbedrijven (gemeten als $\mathrm{GAR}_{\text {) }}$ ) significant groter moeten zijn dan de underperformance die de aandelenintroducties van particuliere ondernemingen laten zien. Bij privatiseringen is er immers sprake van een grotere mate van overoptimisme als gevolg van buitengewoon grote publiciteit rondom de aandelenintroductie van staatsbedrijven.

Volgens de underpricing-hypothese, daarentegen, zou er geen significant verband bestaan tussen het initieel rendement en het aftermarket rendement van aandelenintroducties. Bovendien wordt geen sterkere underperformance verwacht bij aandelenintroducties van staatsbedrijven dan bij aandelenintroducties van particuliere ondernemingen.

\section{Data}

De periode waarop dit onderzoek betrekking heeft, strekt zich uit van 1 januari 1979 tot en met 31 december 1991. Het grootste deel van de aandelenintroducties van staatsbedrijven is wereldwijd na 1979 aangeboden. (In 1979 ging het omvangrijke Engelse privatiseringsprogramma, dat voor diverse landen als voorbeeld heeft gediend, van start.) Om deze reden is als begindatum van de onderzoekperiode 1 januari 1979 gekozen. De aandelenmarkten die in het onderzoek opgenomen worden, zijn volgens twee criteria geselecteerd:

1 De beurs in kwestie moet meerdere aandelenintroducties van staatsbedrijven toegelaten hebben. Dit om enig betrouwbaar inzicht te verwerven in het koersverloop van de aandelenintroducties en om statistische analyse te 
faciliteren. Gekozen is voor een drempelwaarde van acht aandelenintroducties van staatsbedrijven in de periode 1979-1991.

2 De beurs in kwestie moet een marktkapitalisatie van voldoende omvang hebben om betrouwbare koersinformatie op te leveren. Dit criterium is vooral van belang om een aantal minder liquide beurzen uit te sluiten (onder andere in Latijns-Amerika). Gekozen is voor een drempelwaarde van US\$ 50 miljard ultimo 1991.

De beurzen van Londen (VK), Singapore, Toronto (Canada). Kuala Lumpur (Maleisië) en Parijs (Frankrijk) voldoen aan beide criteria; de overige beurzen voldeden aan slechts een of geen van de genoemde criteria.

In tweede instantie zijn de beurzen van Parijs en Kuala Lumpur uitgesloten wegens het afwijkende emissiemechanisme dat gebruikt wordt bij aandelenintroducties in de onderzoekperiode ${ }^{7}$.

Voor de beurzen van Londen. Singapore en Toronto is voor alle aandelenintroducties, die in de periode 1979-1991 door middel van een openbare emissie tegen een vaste uitgiftekoers aangeboden zijn de uitgiftekoers alsmede de slotkoers op de eerste handelsdag, op de dag één, twee en drie jaar na introductie uit de databank van Datastream overgenomen. Omdat Datastream de koersen niet corrigeert voor dividenden, is de koersindex van Morgan Stanley Capital International gebruikt voor de berekening van de initiële en aftermarket rendementen van de aandelen die geïntroduceerd zijn op de beurzen van Londen en Toronto. Voor

Tabel 2: In de dataset opgenomen aandelenintroducties van staatsbedrijven en particuliere ondernemingen; beurs van Londen, Singapore en Toronto 1979-1991

\begin{tabular}{|c|c|c|}
\hline & $\begin{array}{c}\text { Aandelenintroducties van } \\
\text { particuliere ondern. }\end{array}$ & staatshedrijen \\
\hline \multicolumn{3}{|c|}{ Berekening van } \\
\hline \multicolumn{3}{|c|}{ initiële rendementen } \\
\hline Londen & 193 & 38 \\
\hline Singapore & 75 & 12 \\
\hline Toronto & 169 & 8 \\
\hline \multicolumn{3}{|c|}{ Berekening ran } \\
\hline \multicolumn{3}{|c|}{ aftermarket rendementen } \\
\hline Londen & 173 & 38 \\
\hline Singapore & 59 & 12 \\
\hline Toronto & 121 & 7 \\
\hline
\end{tabular}

de aandelen die geïntroduceerd zijn op de beurs van Singapore is de Straits Times Industrial Index gebruikı. omdal Morgan Stanley Capital International voor een gedeelte van de onderzoekperiode (1979-1991) een gecombineerde beursindex voor Singapore/Maleisië berekent.

Een en ander resulteert in de dataset die beschreven is in tabel 2 .

De dataset die gebruikt is om de initiële rendementen te berekenen, bevat alle aandelenintroducties die gedaan zijn in de periode 1979 1991. De reden voor het geringere aantal aandelenintroducties van (met name) particuliere ondernemingen dat gebruikt is om de aftermarket rendementen te berekenen, is dat een deel van de geïntroduceerde bedrijven in de onderzoekperiode verwijderd is uit de databank van Datastream.

Omdat Datastream niet aangeeft waarom deze verwijdering heeft plaatsgevonden (de diverse mogelijkheden zijn. bijvoorbeeld. overname, faillissement of omzetting van genoteerde naar niet-genoteerde onderneming). heeft er in dit onderzoek geen correctie voor de uiteenlopende effecten van de diverse genoemde mogelijkheden platsgevonden.

Dalarnaast dient opgemerkt te worden dat de bovenstaande atantallen aangaande de berekening van aftermarket rendementen, betrekking hebben op de berekening van $A R_{i}$. Doordat de periode waarover $A R$, en $A R$, berekend worden zich uitstrekt tot voorbij de datum waarop in de databank van Datastream historische koersen vermeld worden, zijn er in het geval van AR, 11 introducties van staatsbedrijven voor de beurs van Singapore in de ditaset opgenomen.

In het geval van $\mathrm{AR}$, zijn de aantallen aandelenintroducties van particuliere ondernemingen en stiatsbedrijven die opgenomen zijn in de dataset, vermeld in tabel 3 .

Tabel 3: In de dataset opgenomen aandelenintroducties van staatsbedrijven en particuliere ondernemingen; beurs van Londen, Singapore en Toronto 1979-1991

\begin{tabular}{lcc}
\hline & $\begin{array}{c}\text { Aandelenintroducties ran } \\
\text { particulicre ondern. }\end{array}$ & stactshedrijien \\
\hline Berckening & & \\
ran $A R$. & 169 & 21 \\
Londen & 51 & 8 \\
Singapore & 118 & 6 \\
Toronto & & \\
\hline
\end{tabular}


ties van particuliere ondernemingen. Echter, uit de resultaten die vermeld zijn in tabel 6 en in figuur 1 worden geïllustreerd blijkt dat het gemiddeld aftermarket rendement $\left(\mathrm{GAR}_{\mathrm{i}}\right)$ van de aandelenintroducties van staatsbedrijven juist hoger is dan dat van de aandelenintroducties van particuliere ondernemingen.

Tabel 6: Gemiddeld aftermarket rendement aandelenintroducties 1 jaar na introductie $\left(G A R_{1}\right), 2$ jaar na introductie (GAR, en 3 jaar na introductie $\left(G_{G} A R_{3}\right)$ staatsbedrijven en particuliere ondernemingen; beurs van Londen, Singapore en Toronto 1979-1991

Aantal GAR \% SD\% 1 -wrd.' 1 -wrd. ${ }^{2}$

Een jaar na introductie (GAR,

Londen

$\begin{array}{lrrrrr}\text { part. ondern. } & 17.3 & 1,99 & 63.76 & 0.41 & -1.06 \\ \text { staatsbedrijven } & 38 & 7.76 & 15.45 & 3.10^{*} & \\ \text { Singapore } & & & & & \\ \text { part. ondern. } & 59 & -11.85 & 34.08 & -2.67^{*} & -0.58 \\ \text { staatsbedrijven } & 12 & -5.30 & 43.44 & -0.42 & \\ \text { Toronto } & & & & & \\ \text { part. ondern. } & 121 & -19.55 & 46.16 & -4.66^{*} & -1.45 \\ \text { staatsbedrijven } & 7 & 6.00 & 24.38 & 0.65 & \end{array}$

Twee jaar na introductie (GAR,

Londen

$\begin{array}{lrrrrr}\text { part. ondern. } & 173 & 3,37 & 95,27 & 0.47 & -1.90 \\ \text { staatsbedrijven } & 38 & 19,96 & 30.09 & 4,09 * & \\ \text { Singapore } & & & & & \\ \begin{array}{l}\text { part. ondern. } \\ \text { staatsbedrijven }\end{array} & 59 & -24,77 & 39.11 & -4,87 * & -1,40 \\ \text { Toronto } & 11 & -5,31 & 56.80 & -0.31 & \\ \text { part. ondern. } & 121 & -34,02 & 47.53 & -7,87 * & \\ \text { stalatsbedrijven } & 7 & 4.97 & 30,00 & 0.44 & -2.14^{*}\end{array}$

Drie jaar ha introductie (GAR,)

Londen

\begin{tabular}{|c|c|c|c|c|c|}
\hline purt. ondern. & 169 & 5,41 & 143.71 & 0.49 & -1.79 \\
\hline sliatsbedrijven & 21 & 33.14 & 50.00 & $3.04 *$ & \\
\hline \multicolumn{6}{|l|}{ Singapore } \\
\hline part. ondern. & 51 & $-31,88$ & 35.73 & $-6.37 *$ & -1.15 \\
\hline stalatsbedrijven & 8 & -1.42 & 73.61 & -0.06 & \\
\hline \multicolumn{6}{|l|}{ Toronto } \\
\hline part. ondern. & 118 & -40.29 & 65.11 & $-6.72 *$ & -0.22 \\
\hline staatsbedrijven & 6 & -34.35 & 69.75 & -1.21 & \\
\hline \multicolumn{6}{|c|}{$\begin{array}{l}*=\text { significant bij een betrouwbaarheidsinterval met } \alpha= \\
0,05 \text { (eenzijdig) }\end{array}$} \\
\hline \multicolumn{6}{|c|}{$1=\mathrm{t}$-waarde voor test of GAR significant verschilt van nul } \\
\hline $2=1-$ waarde vo & 1 of & $\mathrm{GAR}_{1} \mathrm{v}$ & an ande & lenintrod & ucties \\
\hline
\end{tabular}

Grafiek 3: Verschil tussen GAR van andelenintroductios ran startshedrijuen en particuliere ondernemingen: bews van Londen, Singapore en Toronto 1979-1991

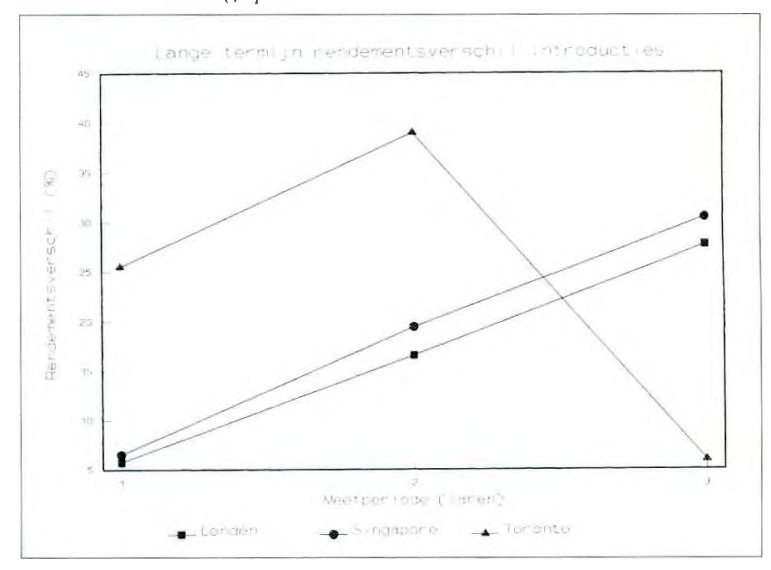

Alleen in het geval van aandelen van particuliere ondernemingen die geintroduceerd zijn op de beurzen van Singapore en Toronto blijki zich een statistisch significante underperformance te ontwikkelen.

Verrassend genoeg laten de aandelen die geintroduceerd zijn op de beurs van Londen een outperformance zien die in het geval van introducties van staatsbedrijven statistisch significant is. Dit is opmerkelijk, aangezien deze aandelenintroducties een hoog en statistisch significant gemiddeld initieel rendement vertonen (zie tabel 4).

Al met al concluderen wij dat de resultaten geen steun verlenen aan de overoptimisme-hypothese.

De veronderstelling dat (door intensieve publiciteit geïnduceerde) overoptimisme tijdens de eerste dagen van handel tol relatief hoge initiële rendementen van aandelenintroducties van staatsbedrijven leidt, wordt niet door de onderzoekresultaten gestaafd.

\section{Conclusies en aanbevelingen}

De diverse alternatieve verklaringen voor het hoge initiële rendement van aandelenintroducties van staatsbedrijven zijn in eerder onderzoek" empirisch getoetst. De conclusie van dat onderzoek dat het hoge initiële rendement van de aandelenintroducties van staatsbedrijven het gevolg is van de doelstelling van de overheid om het aandelenbezit onder burgers te verbreden blijkt niet te conflicteren met het hier gedocumenteerde koersverloop van de introducties op de lange termijn. Over een meerjarige periode blijken 
de aandelenintroducties van staatsbedrijven het niet significant slechter te doen dan het beursgemiddelde.

Om echter de stelligheid waarmee deze conclusie getrokken kan worden, te vergroten, wordt aanbevolen om toekomstig onderzoek verder uit te breiden buiten de beurzen van Londen, Singapore en Toronto. Voorts zou een vergroting van de omvang van de steekproeven die gebruikt zijn in dit onderzoek (en dan met name het aantal aandelenintroducties van Canadese staatsbedrijven) de betrouwbaarheid van de statistische analyse verhogen.

\section{I T E R A T U U R}

Aggarwal, R. en P. Rivoli, (1990), Fads in the initial public offering market?, Financial Management, pp. 45-56.

Aggarwal, R., R. Leal en L. Hernandez, (1993), The aftermarket performance of initial public offerings in Latin America, Financial Management, pp. 42-53.

Bear, R.M. en A.J. Curley, (1975), Unseasoned equity financing, Journal of Financial and Quantitative Analysis, pp. 311-325.

Chalk, A.J. en J.W. Peavy, (1987), Initial public offerings: daily returns, offering types and the price effect, Financial Analysts Journal, pp. 65-69.

Dawson, S.M., (1987), Secondary stock market performance of initial public offers, Hong Kong, Singapore and Malaysia: 1978-1984, Journal of Business Finance and Accounting, pp. $65-76$.

Eijgenhuijsen, H.G., (1989), Aandelenintroducties op de Amsterdamse effectenbeurs en het verschijnsel underpricing, Maandblad voor Accountancy en Bedrijfseconomie, pp. 119-127.

Eijgenhuijsen, H.G. en A. Buijs, (1993), Initial public offerings in the Netherlands 1982-1991. Discussion Paper, voorgedragen tijdens the European Institute for Advanced Management Studies workshop on corporate finance and the stock market, Brussel, 29-30 maart.

Finn, F.J. en R. Higham, (1988), The performance of unseasoned new equity issues-cum-stock exchange listings in Australia, Journal of Banking and Finance, pp. 333-351

Huibers, F.E., (1993), Aandelenintroducties en privatisering het verschijnsel underpricing, Maandblad voor Accountancy en Bedrifseconomie, pp. 290-301.

Huibers, F.E, (1994), The Pricing of Public and Private Sector IPOs: Theory and Evidence, Uitgeverij Eburon, Delft.

Keloharju, M., (1993), The winner's curse, legal liability, and the long-run price performance of initial public offerings in
Finland, Journal of Financial Economics, pp. 251-277.

Levis, M., (1993), The long-run performance of initial public offerings: the UK experience 1980-1988, Financial Management, pp. 28-41.

Loughran, T. (1993), Market microstructure or the poor performance of initial public offerings?, Journal of Financial Economics, pp. 241-260.

McDonaid, J.G. and B.C. Jacquillat, (1974), Pricing of initial equity issues: the French sealed-bid auction, The Journal of Business, pp. 37-48.

Reilly, F.K., (1977), New issues revisited, Financial Management, pp. 28-42.

Ritter, J.R., (1991), The long-run performance of initial public offerings, The Journal of Finance, pp. 3-27.

Saunders, A. and J. Lim, (1990), Underpricing and the new issue process in Singapore, Journal of Banking and Finance, pp. 291-309.

Shiller, R.J., (1990), Speculative prices and popular models, Journal of Economic Perspectives, pp. 55-65.

\section{N O T E N}

1 Zie Dawson (1987).

2 Zie Huibers (1994).

3 In deze studie zullen wij de neutrale term 'initieel rendement' hanteren.

4 In de onderzoeken van Ritter (1991), Loughran (1993), Levis (1993), Aggarwal et al. (1991) en Keloharju (1993) wordt het koersverloop over drie in plaats van een jaar gemeten.

5 Betreffende de 21 aandelen die geïntroduceerd zijn op de beurs van Kuala Lumpur (Maleisië) in de periode 1978-1983.

6 Vergelijking (1) is een variant op de formule zoals die gehanteerd wordt door Eijgenhuijsen (1989). Eijgenhuijsen (1989) berekent het gemiddelde van de eerste vijf slotkoersen ter beurze die voor het geïntroduceerde aandeel tot stand zijn gekomen teneinde de betrouwbaarheid van de gemeten underpricing te verhogen door uitschieters te flatteren.

7 Zie McDonald en Jacquillat (1974) voor de beurs van Parijs en Saunders en Lim (1990) voor de beurs van Kuala Lumpur.

8 De relatief lage standaarddeviatie van het initiele rendement van de aandelenintroducties van staatsbedrijven die op de beurs van Toronto hebben plaatsgevonden, is wellicht het gevolg van het disproportioneel frequent gebruik van de overallotment optie (green shoe) in het geval van deze aandelenintroducties. Voor een gedetailleerde bespreking van het effect van deze optie op de initiële rendementen, verwijzen wij naar Huibers (1993).

9 Zie Huibers (1994). 